\title{
ALGUMAS DIMENSÕES DO MERCADO DA BIODIVERSIDADE EM MANAUS-AM
}

\section{SOME DIMENSIONS OF BIODIVERSITY MARKET IN MANAUS-AM}

\section{ALGUNAS DIMENSIONES DEL MERCADO DE LA BIODIVERSIDAD EN MANAUS-AM}

\author{
Bárbara Evelyn da Silva Ferreira \\ Laboratório de Estudos Sociais - LAES; Núcleo de Pesquisa em Ciências \\ Humanas e Sociais - NPCHS; Instituto Nacional de Pesquisas da Amazônia - INPA \\ Av. André Araújo, 2936, Aleixo, CEP 69060-001, Manaus - AM \\ E-mail: bah_evelyn@hotmail.com

\section{Reinaldo Corrêa Costa} \\ Laboratório de Estudos Sociais - LAES; Núcleo de Pesquisa em Ciências \\ Humanas e Sociais - NPCHS; Instituto Nacional de Pesquisas da Amazônia - INPA \\ E-mail: rei@inpa.gov.br \\ Cecilia Veronica Nunez ${ }^{2}$ \\ Laboratório de Bioprospecção, Coordenação de Pesquisas em Produtos \\ Naturais - CPPN, Instituto Nacional de Pesquisas da Amazônia - INPA, \\ E-mail: cecilia@inpa.gov.br
}

\section{Resumo}

O mercado dos bioprodutos em Manaus envolve a comercialização de plantas medicinais, oriundas da biodiversidade, e o etnoconhecimento vem para fundamentar a venda e logo o lucro dos sujeitos sociais envolvidos neste processo. É com base nestes conhecimentos que as pessoas comercializam e, muitas vezes, fazendo prescrições do uso dessas plantas. Outro ramo do mercado da biodiversidade é a produção e comercialização de bioprodutos (fitoterápicos e fitocosméticos), que tem em sua base a biodiversidade da região.

Palavras-chave: Etnoconhecimento, mercado, biodiversidade, bioprodutos.

\begin{abstract}
The bio-products market in Manaus involves the medicinal plants trade, derived from biodiversity, and ethnoknowledge comes to support the sale and then the profit of those involved in this process. It is based on this knowledge that people who sell and often prescribing it. Another biodiversity market segment is the production and marketing of bio-products (herbal medicines and cosmetics), which has its basis on the region's biodiversity.
\end{abstract}

Keywords: Ethnoknowledge, market, biodiversity, bio-products. 


\section{Resumen}

El mercado de los bioproductos en Manaus abarca la comercialización de plantas medicinales, derivadas de la biodiversidad y el conocimiento tradicional viene a fundamentar la venta y luego el lucro de los sujetos sociales envueltos en este proceso. Es embasado en este conocimiento que las personas venden $\mathrm{y}$, a menudo haciendo prescripciones del uso de esas plantas. Otro segmento del mercado de la biodiversidad es la producción y comercialización de bioproductos (fitoterápicos y fitocosméticos), que tiene como base la biodiversidad de la región.

Palabras clave: Conocimiento tradicional, mercado, biodiversidad, bioproductos.

\section{Introdução}

Este trabalho visa construir elementos para o conhecimento da realidade empiricamente observada a respeito dos processos geográficos (espaciais, territoriais e paisagísticos) que concretizam relações entre sociedade e natureza, circulação espacial de renda e transformações na agricultura familiar, como os que ocorrem no município de Manaquiri (AM), onde o conhecimento tradicional está sendo associado a modernidades, técnicas/tecnologias, para assim fazerem extração dos óleos vegetais que são matéria-prima para os bioprodutos (fitoterápicos e fitocosméticos) comercializados em Manaus-AM. Neste município pode-se observar a relação entre sociedade e natureza que se estabelece entre os membros da Cooperativa de Produtores e Beneficiadores de Plantas Medicinais, de Fitoterápicos e Fitocosméticos de Manaquiri AM (COOPFITOS) e a biodiversidade.

Outro fator neste mercado é a comercialização de plantas medicinais nas feiras e lojas de Manaus. Este processo utiliza o conhecimento tradicional dos sujeitos sociais envolvidos (feirantes, lojistas), principalmente em relação à utilidade e aplicabilidade da plantas medicinais. Um dos principais sujeitos sociais envolvidos nesta etapa é o atravessador, pois é deste que geralmente os comerciantes, seja das feiras ou das lojas, adquirem os produtos para a venda. Com isto, um atravessador do município de Itapiranga (AM), é um dos fornecedores de algumas lojas e feirantes de Manaus.

Parte da matéria-prima dos bioprodutos comercializados na capital amazonense geralmente vem do interior do Estado, coletados por camponeses, e a economia destes "se caracteriza por formas extensivas de ocupação autônoma (ou, seja trabalho familiar), pelo controle dos próprios meios de produção [...]" (Shanin, 1980, p. 46), e 
assim, são vendidos e transportados para as indústrias, que transformam estes produtos, que posteriormente, são levados para o comércio. Logo a escala espacial dos bioprodutos passa pela produção, comercialização, transformação e comercialização', que é feita por diferentes sujeitos sociais, em diferentes circuitos e escalas de economicidade e mercado em diferentes tempos de produção.

Com a industrialização, a comercialização dos bioprodutos é facilitada, pois os produtos antes produzidos de maneira artesanal são agora feitos com rapidez e com as regularidades impostas pelas agências legais, pelos consumidores e principalmente pela Agência Nacional de Vigilância Sanitária (ANVISA). Desta maneira, no mercado dos bioprodutos em Manaus, esta mercadoria é comercializada de diferentes maneiras, seja em shoppings, lojas ou feiras. A cadeia produtiva dos bioprodutos inicia-se com trabalho camponês que fornece matéria-prima in natura, que ao ser beneficiada nas indústrias de Manaus, São Paulo, na COOPFITOS, entre outras é a base para os bioprodutos.

\section{Biodiversidade}

No mercado da biodiversidade polarizado em Manaus é notável a utilização do etnoconhecimento pelos produtores, principalmente os que estão no interior do Estado. Mesmo sem tecnologias avançadas, por meio do conhecimento tradicional é possível a utilização das potencialidades da natureza em outro tipo de relação onde há pouca intensidade de conhecimento técnico-científico, e "este conjunto de conhecimentos e comportamentos constitui um patrimônio cultural que é transmitido de geração em geração" (Lévêque, 1999, p. 218). A utilização das plantas medicinais é intensificada, tendo o atravessador como o sujeito econômico que realiza a distribuição e/ou a circulação da mercadoria desde o momento que ela é recurso natural na floresta até sua forma de produto final que chega nas feiras, lojas de Manaus, e com isto ao consumidor final.

As plantas medicinais, oriundas da biodiversidade, são utilizadas como matériaprima in natura (FIGURA 01), que ao serem beneficiadas em extratos, óleos vegetais e essenciais, são utilizadas como matérias-prima pelas empresas de fitoterápicos e cosméticos (FIGURA 02) de Manaus. Para a produção dos fitoterápicos a Agência Nacional de Vigilância Sanitária (ANVISA) adverte que a eficácia e segurança devem 
ser validadas "através de levantamentos etnofarmacológicos, documentações tecnocientíficas em bibliografia elou publicações indexadas e/ou estudos farmacológicos e toxicológicos pré-clínicos e clínicos". (Medicamentos Fitoterápicos, ANVISA. EM: 14/05/2010), ou seja, não basta os empresários terem apenas o etnoconhecimento, os fitoterápicos tem que ter aplicabilidade farmacológica e serem devidamente registrados na ANVISA.

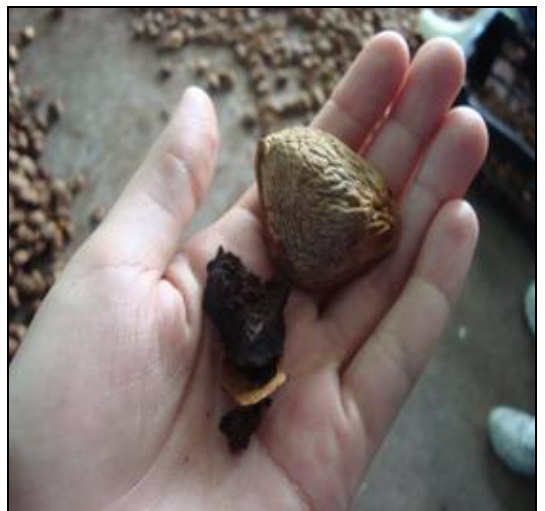

Figura 01 - Andiroba - matéria-prima in natura - utilizada pela COOPFITOS em Manaquiri (AM) para realizar a extração do óleo vegetal, que é comercializado para empresas de Manaus e São Paulo. Na atualidade a andiroba é a principal matéria-prima utilizada pelos cooperados para a extração de óleo no município. Março de 2010.

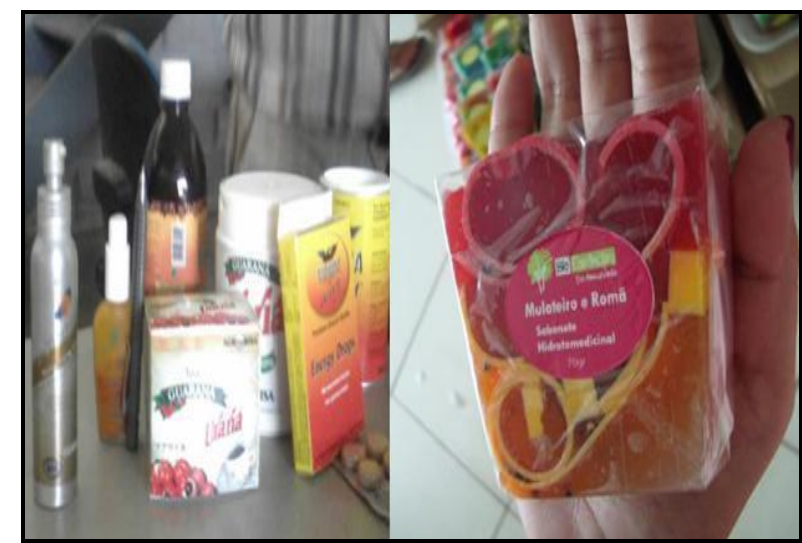

Figura 02 - Bioprodutos. À esquerda são os Fitoterápicos à base de guaraná, comercializados pela empresa em lojas de Manaus e exportados para Itália, França, Alemanha, Suiça, Estados Unidos, entre outros, sendo a principal dificuldade do empresário adequar-se as normas dos outros países. À direita o Fitocosmético à base de mulateiro e romã, comercializado por outra empresa de Manaus em feiras e stands em shoppings. Março de 2010.

$\mathrm{Na}$ atualidade, pela atenção que a mídia tem dado a questão dos fitoterápicos, vem-se discutindo bastante sobre a utilização, a eficácia ou não destes bioprodutos. Neste caso, no momento, o que mais tem causado discussões sobre o assunto é a série “É bom pra quêe", exibida no Fantástico - Rede Globo, apresentada por Dráuzio Varella, 
segundo ele "o objetivo da série é discutir os usos e abusos dos tratamentos médicos feitos com produtos derivados de plantas que não passaram pelo crivo científico dos estudos clínicos, e analisar as perspectivas da fitoterapia medicinal." (É bom pra quê, FANTÁSTICO. EM: 07/09/2010).

O médico, afirma que esses fitoterápicos devem ser estudados e analisados nas suas potencialidades, e de acordo com ele, "a fitoterapia medicinal só será levada a sério quando for muito além do chazinho; quando tivermos preparações padronizadas, acompanhadas de bulas com instruções de preparo, dosagens, indicações, contraindicações, efeitos colaterais e toxicidade." (É bom pra quê, FANTÁSTICO. EM: 17/09/2010).

Ele não faz menção à quantidade de estudos (pesquisas, teses, dissertações e monografias) sendo realizados no Brasil sobre as plantas, sejam elas medicinais ou não. Consultando o site do $\mathrm{CNPq}$, é possível ver quantos grupos de pesquisa realizam estudos, desenvolvendo estudos científicos sobre a química e a farmacologia das plantas e de seus extratos e óleos. Se não há muitos fitofármacos registrados na ANVISA, isto é por questões geopolíticas e geoeconômicas, assim como pela dificuldade em realizar todos os estudos químicos e farmacológicos, seja pela falta de apoio financeiro das empresas. No entanto, isso não desmerece o trabalho de tantos cientistas pesquisando nas instituições de pesquisa brasileiras. Essa diferenciação deveria ter sido feita no programa.

Apesar das poucas comprovações da eficácia dos fitoterápicos, que tem em sua base as plantas medicinais, o mercado da biodiversidade, nos últimos dez anos vem crescendo em Manaus, e a biodiversidade utilizada nesse processo, economicamente, segundo Lévêque (1999), "contribui para o fornecimento de numerosos produtos alimentares, matérias-primas para a indústria, medicamentos, materiais de construção e de uso doméstico" (p. 14). Sendo assim, a biodiversidade é matéria-prima in natura, $e$ ao ser beneficiada em extratos (FIGURA 03) e óleos constitui-se a base para os bioprodutos. 


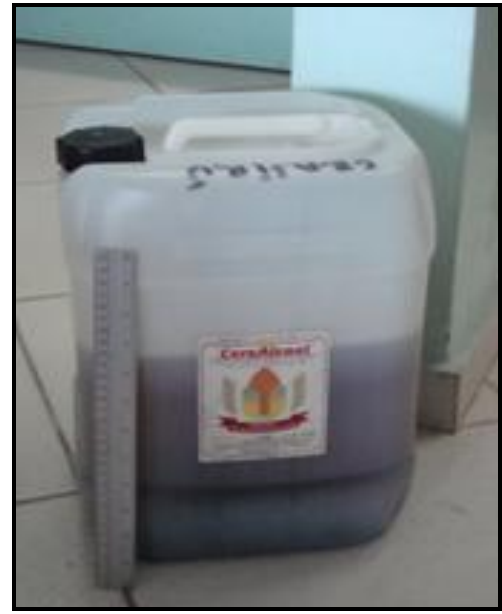

Figura 03 - Matéria-prima beneficiada, neste caso, extrato de crajirú, utilizado por uma empresa de Manaus para produzir fitoterápicos, comercializados em feiras de Manaus e lojas da empresa. Março de 2010.

\section{As indústrias e biodiversidade}

A biodiversidade é a matéria-prima dos denominados bioprodutos. As bioindústrias buscam apropriar-se comercialmente do uso social da biodiversidade, ou seja, os recursos naturais, tornando a relação sociedade natureza evidentes no processo de formação de mercadorias, que através das técnicas e tecnologias tornam possível o beneficiamento de tais recursos.

Parte da matéria-prima, no caso, os óleos vegetais usados por algumas empresas de Manaus vem da COOPFITOS que está instalada no município de Manaquiri. Esta é uma cooperativa de extração de óleos (no momento, babaçu e andiroba), que possui uma agroindústria (FIGURA 04) para o beneficiamento da matéria-prima in natura. No início, nesta cooperativa a extração era feita de maneira artesanal, sem grandes técnicas/tecnologias, hoje eles possuem infra-estrutura (máquinas) para fazer a extração. Para adquirirem a infra-estrutura, a cooperativa fez parcerias com bancos, por meio do Serviço Brasileiro de Apoio a Micro e Pequenas Empresas do Amazonas (SEBRAE $\mathrm{AM})$ 


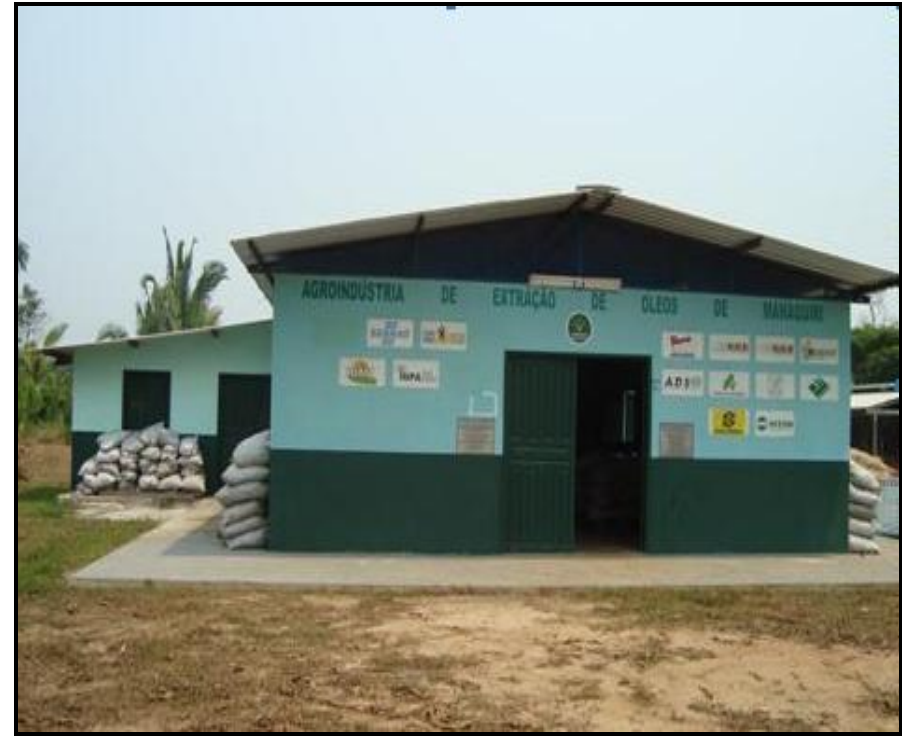

Figura 04 - Agroindústria de Extração de óleos, localizada em Manaquiri (AM), que fornece matériaprima para os bioprodutos, utilizados pelas empresas de Manaus e São Paulo. Além da extração de óleos vegetais, os cooperados também produzem cosméticos, mas ainda em pequena quantidade e em escala local. Agosto de 2010

As necessidades das sociedades as levam a transformar e ou se apropriar da natureza, desse modo, "é no processo de busca da satisfação de suas necessidades materiais que o homem trabalha, transformando a natureza, produzindo conhecimento e criando a si mesmo (ANDERY et al, 1988, p. 416)", objetivando como benefício, lucro ou mesmo potencialidades que a natureza pode oferecer.

Para usufruir das potencialidades econômicas da natureza, os cooperados utilizam meios técnicos que não faziam parte de seu cotidiano, isto é, infra-estrutura para a cooperativa, principalmente máquinas e equipamentos. As técnicas/tecnologias começam a fazer parte do cotidiano dos cooperados, e segundo Damiani (2007) "a base tecnológica e econômica pode sugerir sociedades concretamente diferentes, pois não se faz tábula rasa das maneiras de viver, dos costumes, dos simbolismos de um povo de forma absoluta, por mais rigorosos que sejam os processos reprodutores envolvendo empresas e estratégias políticas" (p. 162); no município de Manaquiri, houve a inserção de novas técnicas, nos meios de produção, o trabalho que era realizado totalmente manual pelos cooperados, agora é realizado com o auxilio de máquinas, que foram adquiridas por meio de financiamentos em bancos, diminuindo o tempo gasto para se fazer o produto e aumentando a produção e instaurando uma "nova" relação de trabalho em Manaquiri. 


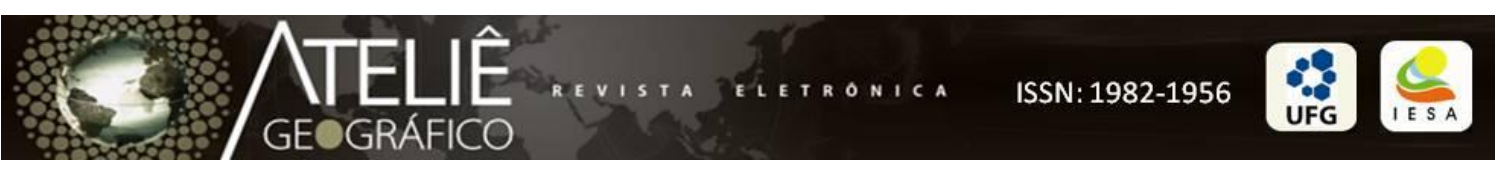

Contudo, os cooperados continuaram com características básicas de seu modo de vida de base camponesa, como o trabalho familiar, a ajuda mútua, para melhor desenvolverem as atividades da cooperativa, e para que haja o aumento da produtividade, com objetivo de superar as adversidades financeiras. A subordinação formal do trabalho camponês ao capital (Santos, 1978, p. 125), via processos de inserção de bioprodutos que plasma uma dinâmica de territorialização do capital mediada pelo trabalho cooperativo como contradição da existência camponesa.

De acordo com Lévêque (1999), "o fato marcante dos últimos anos é o da tomada de consciência que a biodiversidade tornou-se uma verdadeira aposta industrial e comercial" (p. 117), e com as inovações tecnológicas e o avanço da ciência, principalmente da fitoquímica, isso se torna cada vez mais acessível, e a relação sociedade-natureza torna-se mais constante, tecnificada e mercantil, e "o avanço tecnológico é uma força essencial por trás do crescimento econômico" (Krugman e Wells, 2007, p. 521).

$\mathrm{Na}$ COOPFITOS, com os financiamentos obtidos, a cooperativa pode investir na compra de equipamentos para realizar a extração dos óleos que são comercializados para as empresas de Manaus, ou de outras cidades, como São Paulo. O que produz uma espacialidade dos óleos, com circuitos e escalas de economicidades próprias, e com sujeitos econômicos e sociais distintos nos diferentes lugares.

Muitas empresas em Manaus adquirem matéria-prima beneficiada em São Paulo, pois nesta cidade há uma aglomeração de empresas que comercializam óleos essenciais e vegetais, extratos, assim como embalagens, em Manaus não há matéria-prima beneficiada suficiente para suprir este mercado, e quando têm, estas acabam por não serem economicamente viáveis, assim, São Paulo, como centro gravitacional e como força centrípeta, instaura possibilidades de ampliação do espaço da biodiversidade industrializada.

Desta maneira muitos empresários, indagam sobre a falta de empresas especializadas neste tipo de atividade em Manaus, e falam sobre a falta de incentivo neste setor por parte do Estado, tendo em vista que a COOPFITOS não a necessidade de matéria-prima para os bioprodutos.

\section{Comercialização de plantas medicinais e o etnoconhecimento}


$\mathrm{Na}$ "Feira da Manaus Moderna" em Manaus (centro da cidade) são comercializadas, dentre outras mercadorias, as chamadas plantas medicinais, em um setor específico da feira já territorializado com este tipo de mercadoria. Nesta feira, que é um espaço com grande circulação de capital para expor e vender mercadorias, os comerciantes utilizam o conhecimento adquirido, na maioria das vezes hereditariamente, para comercializar seus produtos. Os feirantes das feiras ao vender as plantas medicinais, utilizam o etnoconhecimento para facilitar o processo de comercialização.

Ocorre que, estes acabam por estabelecer certa funcionalidade à planta que eles estão vendendo, como exemplo, a planta X serve para tratar a doença Y. As plantas medicinais (FIGURA 05), muitas vezes são cultivadas pelo próprio vendedor, que ao comercializá-las, deixam de ter valor-de-uso, para tornar-se valor-de-troca, pois “é a realização prática, no mercado, de seu valor de troca que faz essa transformação efetuarse, pois somente o que, no objeto é comparável com outros objetos permite o processo de troca, isto é, a entrada em sociedade" (Pignarre, 1999, p. 83), e ao chegar ao consumidor final voltam a ter valor-de-uso, com isto, segundo Marx (1995), “a utilidade de uma coisa faz dela um valor-de-uso" (p. 53).

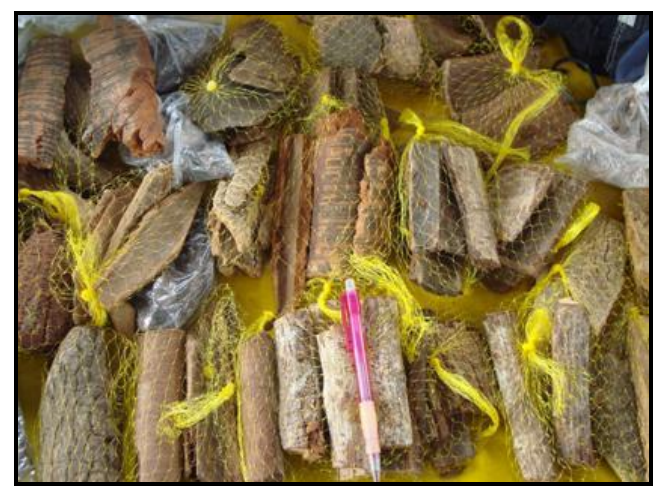

Figura 05 - Plantas Medicinais, comercializadas em uma feira no município de Careiro Castanho (AM), no qual o feirante adquire a mercadoria em sua própria propriedade ou por meio de atravessadores, sendo uma prática comum nesta feira a comercialização de plantas medicinais, assim como em um setor da feira da Manaus Moderna. Março de 2010.

As pessoas que comercializam nas feiras também têm acesso às plantas medicinais por meio de lojas, principalmente uma localizada no centro da cidade, que também comercializa outros produtos como "tratamento alternativo", como cereais, 
sementes, entre outros, que segundo, o gerente, "pode ajudar nos cuidados com a saúde das pessoas". Esta loja é também um dos principais fornecedores para os feirantes da cidade.

Outra maneira dos vendedores adquirirem mercadorias para comercializar na feira, é por meio dos atravessadores. Estes por sua vez, buscam as plantas medicinais em municípios do Estado, e fornecem tanto para os vendedores da feira quanto para as lojas de Manaus.

Assim, a mercadoria, que segundo Marx (1995), "é um objeto externo, uma coisa que, por suas propriedades, satisfaz necessidades humanas, seja qual for a natureza, a origem delas, provenham do estômago ou da fantasia" (p. 53), começa sua espacialidade no campo, pois o atravessador adquire as mercadorias dos produtores rurais. A espacialidade das plantas medicinais passa pelas etapas de produção, distribuição, circulação e consumo, que constituem sua cadeia produtiva (DIAGRAMA 01).

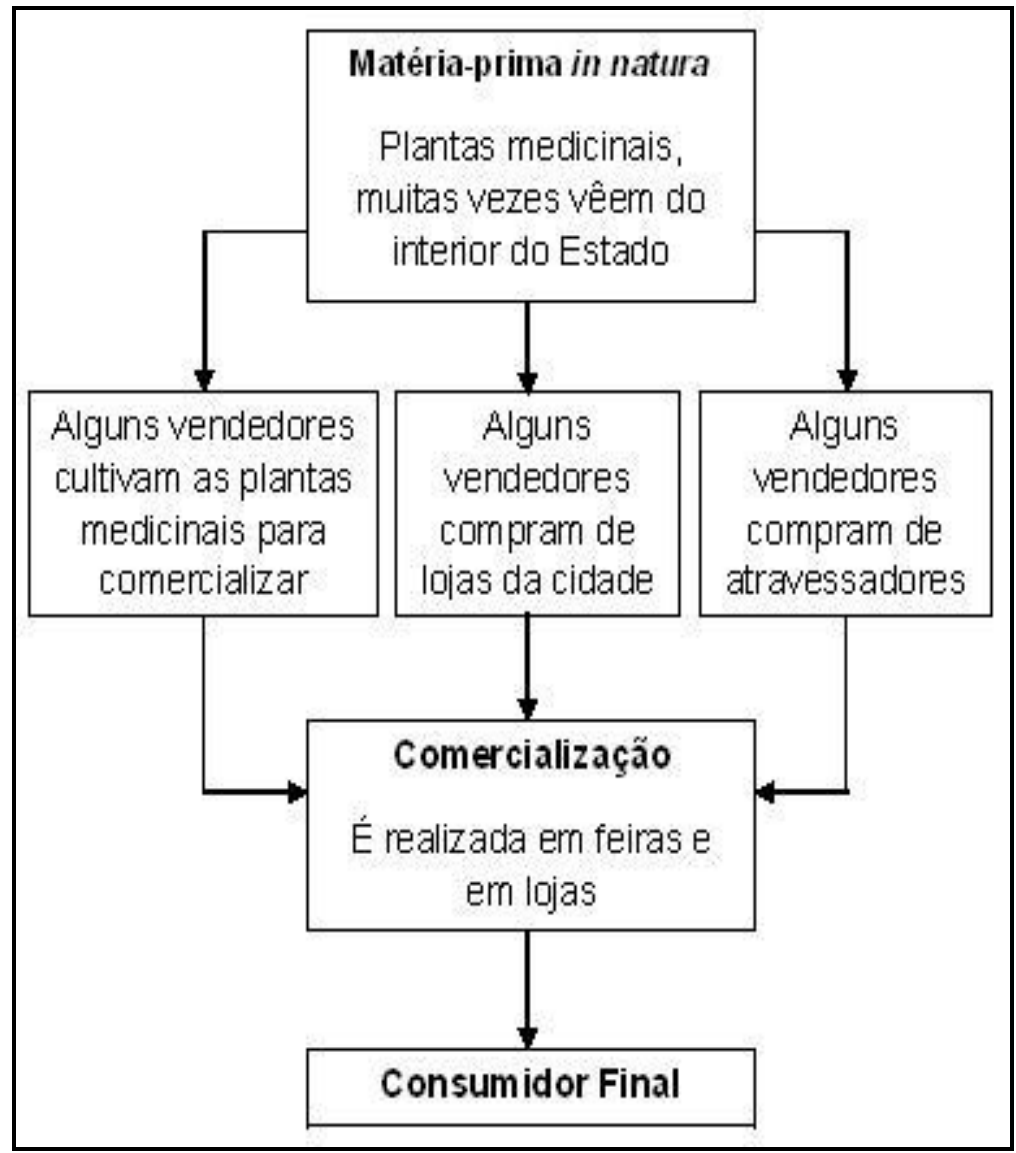

Diagrama 01 - Espacialidade das plantas medicinais. Neste caso, tendo como base os produtores rurais ou os atravessadores de municípios do Estado do Amazonas, que fornecem as plantas medicinais, 
passando em seguida para os feirantes e lojistas de Manaus, chegando diretamente ao consumidor final ou sendo beneficiadas em bioprodutos, e assim chegando ao consumidor final.

\section{O atravessador}

O atravessador é o sujeito social determinante para o mercado das plantas medicinais, pois este é quem traz para Manaus esta mercadoria. È um elemento da circulação no espaço cujo território é definido pela ação no mercado.

De acordo Martins (2000), “é a circulação da mercadoria que diz quanto ela vale e não apenas nem fundamentalmente a sua produção, porque é na circulação que o valor nela contido se revela, (p. 30)", isto não só em relação ao preço da mercadoria final, pois segundo um dos atravessadores entrevistados, ele segue as "regras das pessoas que compram" também no processo de coleta, por exemplo, o Uxi liso amarelo tem que ser batido, o tamanho das cascas quando vem pra Manaus para comercialização tem que ser como o cliente quer.

Este fala que na coleta às vezes necessita derrubar a árvore, como exemplo ele cita a Carapanaúba, "é ruim pra tirar, tem que derrubar”, ele refere-se à casca da árvore, pois a casca na parte superior da árvore é melhor, fazendo com que tenha que derrubar, quando isto ocorre, ele paga cerca de $\mathrm{R} \$ 100,00$ (cem reais) para o dono da propriedade onde a árvore se encontra. Após a coleta, as plantas medicinais, precisam ser secas ao sol, com isso muitas vezes ele tem problema com chuvas, pois quando esta chega, ele tem que rapidamente cobri-las, sendo uma das dificuldades dele. Este vai à procura das plantas medicinais em todo o Estado, compra de produtores rurais (paga a estes por quantidade ou por árvore), e ressalta que no inverno é mais complicado. "Não tem tudo junto", ele refere-se que muitas vezes tem que ir da várzea para terra firme, ou viceversa.

$\mathrm{O}$ atravessador utiliza seus conhecimentos para adquirir as plantas medicinais, desde a coleta (produção), pois este necessita saber onde as plantas estão, como tirá-las, quanto tempo por para secar ao sol, entre outros, e também no momento em que tem que comercializar, pois geralmente as clientes perguntam "para quê que serve" determinada planta.

De acordo com ele, são muitos os gastos para trazer as mercadorias para Manaus (sendo o transporte o maior): transporte na coleta, alimentação na coleta, diária dos 
ajudantes ( $R$ \$ 25,00 vinte e cinco reais), a compra das plantas medicinais, transporte para Manaus (este traz as mercadorias de caminhão ou barco) e o retorno. E complementa dizendo que tudo isto influencia no preço final de tais produtos.

Assim pode-se observar a espacialidade das plantas medicinais trazidas a Manaus pelo atravessador (DIAGRAMA 02). A produção se faz na coleta e no processo de secagem e beneficiamento (cortá-las). A distribuição, segundo Oliveira (1990), "no capitalismo, é a fração da riqueza expressa no salário, no lucro, e na renda da terra" (p. 85), com isto, o atravessador cita que "o lucro em geral é bom, mas é dividido", referindo-se aos gastos que ele tem em todo o processo, e como exemplo cita que ao vender uma saca de Sara-tudo por duzentos e cinqüenta a trezentos reais ( $\mathrm{R} \$ 250,00$ a $300,00)$, ele lucra em média cem reais $(\mathrm{R} \$ 100,00)$.

A circulação "momento do processo econômico onde se dá a circulação efetiva das mercadorias e das pessoas; trata-se no capitalismo da etapa onde se dá a conversão da mercadoria em dinheiro aumentado (M - D')" (Oliveira, 1990, p. 84), ou dinheiromercadoria-dinheiro' (D-M-D'), é a etapa onde a mercadoria chega ao mercado, e há a extração da mais-valia. No caso do atravessador, ele tem seus clientes fixos, e trabalha sob encomenda destes, pois assim, segundo ele, ele tem a segurança de compra da mercadoria que traz para Manaus para ser comercializada. Com isto, chega-se ao consumo, que de acordo com Oliveira (1990), é o "momento no qual se finaliza o processo econômico e ao mesmo tempo se reinicia o mesmo, pois o ato de consumir está imbricado no ato de produzir" (p. 84). 


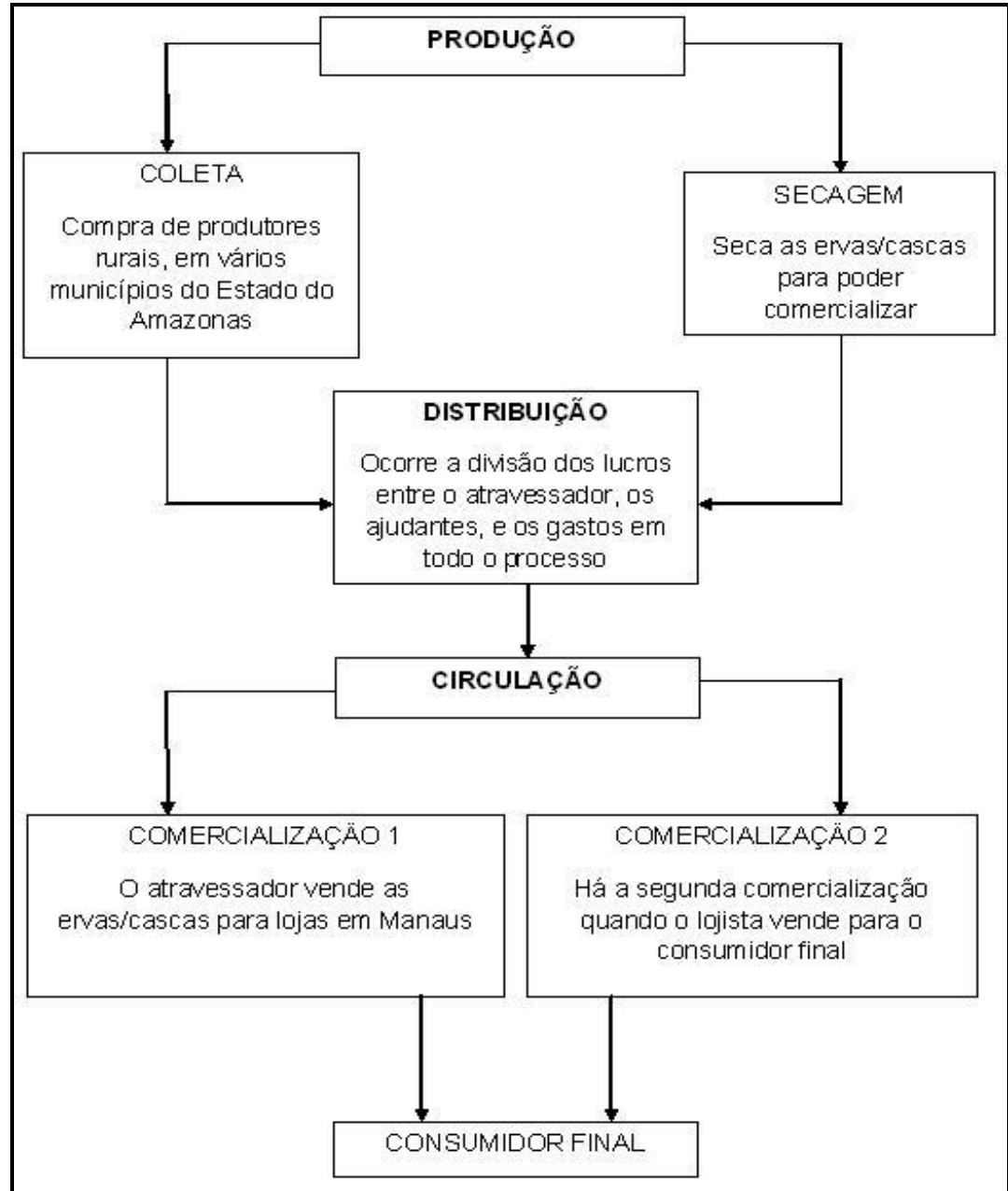

Diagrama 02 - Espacialidade das plantas medicinais por meio do atravessador. Este sujeito social faz com que haja a distribuição e a circulação das mercadorias, chegando diretamente por ele ao consumidor final (em menor quantidade), ou ao lojista e feirantes, para poder chegar ao consumidor final.

\section{Considerações finais}

A biodiversidade é constituída de uma base natural, no caso os geossistemas e de sua existência na formação socioeconômica de base territorial. A biodiversidade se articula em proximidade e afastamento dos modos de vida, das classes sociais e de renda e do Estado e Poderes públicos, assim como do uso do território, de formação e conteúdo de paisagem e de possibilidades de cidadania (inclusão e exclusão de terra, de propriedade da terra) e de justiça espacial.

O modo como são utilizados os produtos da biodiversidade por certos modos de vida cuja relação monetária não é cotidiana, ou quando não há industrialização, 
geralmente são repassados como elemento da cultura e do modo de vida; e em boa parte são usados por mulheres, pois elas utilizam esses conhecimentos para curar doenças e para usar como produtos de beleza, isso é feito sem utilização de conhecimentos refinados da ciência e sem tecnologias de ponta, é outra realidade, é outro contexto do uso social da biodiversidade.

Com os processos de industrialização, as regras de higiene e saúde pública desses produtos, esse conhecimento tradicional fica precisando de um apoio dos conhecimentos da ciência, já que processos mais modernos realizam com mais eficiência, higiene e rapidez a transformação da matéria-prima em bioprodutos, facilitando a comercialização e agregando valor, e assim colocando mais bioprodutos nos mercados a diferentes preços para diferentes consumidores, ampliando a dinâmica de consumo de produtos com forte apelo comercial.

O mercado da biodiversidade em Manaus ainda não está solidificado, pois muitos destes produtos discutidos em escala mundial ainda estão restritos ao comércio local ou regional, conforme o depoimento de um micro-empresário, "ainda estamos buscando mercado, não há mercado consolidado".

O mercado reforça a bioindústria e a biodiversidade, mas não ocorre o mesmo com a territorialidade camponesa ou com seu modo de vida e o direito à terra, ainda que o modo de produção e o sistema produtivo se conectem na satisfação das necessidades dos camponeses, dos mercados e das indústrias.

O mercado da biodiversidade em Manaus tem diferentes agentes, desde a base econômica camponesa, o comerciante, os agentes do Estado e os industriais, em cada um há um processo próprio de relação mercado-mercadoria que diferencia os sujeitos sociais, e cada processo é componente de territorialidades e o bioproduto se insere com contexto dos espaços econômicos. Não se trata do moderno e do atrasado, mas de formas diferentes de se relacionar com a natureza, mas a mediação em ambos os casos é pelo mercado, a intensidade de conhecimentos científicos ou de etnoconhecimento reflete e é refletida como processo espacial de múltiplas dimensões que o mercado não unificou, pois há produtos da grande indústria e produtos de bases camponesas, mas como o rótulo de bioproduto ou produto natural têm grande aceitação no mercado e nas agências de financiamento, a sua produção poderia gerar oportunidade de melhoria de vida para uns, além da acumulação de capital, já observada, para outros. 
Os autores agradecem ao CT-Agro/CNPq pelo apoio financeiro e a bolsa concedida

\section{Referências Bibliográficas}

AGÊNCIA NACIONAL DE VIGILÂNCIA SANITÁRIA (ANVISA). Medicamentos fitoterápicos. Disponível em: <http://www.anvisa.gov.br> Acesso em: 14 de maio de 2010;

ANDERY, Maria Amália et. al. A Prática, a História e a Construção do Conhecimento: Karl Marx (1818-1883). In: Pra Compreender a Ciência. Rio de Janeiro: Espaço e Tempo, 1988;

DAMIANI, Amélia Luisa. O lugar e a produção do cotidiano. In: CARLOS, A. F. A. (Org.). Novos Caminhos da Geografia. 5. Ed. São Paulo: Contexto, 2007, p. 143-172;

FANTÁSTICO. É bom para quê?. Disponível em: <http://fantastico.globo.com/Jornalismo/FANT/0,,MUL1617104-15605,00.html>. Acesso em: 07/09/2010 e 17/09/2010;

KRUGMAN, Paul R.; WELLS, Robin. Introdução à Economia. Tradução de Helga Hoffmann. Rio de Janeiro: Elsevier, 2007;

LÉVÊQUE, Christian. A Biodiversidade. São Paulo: EDUSC, 1999;

MARTINS, José de Souza. A Batalha do Conhecimento e o Fundamentalismo Popularista. In: Reforma Agrária. O Impossível Diálogo. São Paulo: EDUSP, 2000;

MARX, Karl. A Mercadoria: os fundamentos da produção da sociedade e do seu conhecimento. FORACCHI, Mariane M.; MARTINS, José de Souza (orgs.). Sociologia e Sociedade (Leitura de Introdução à Sociologia). São Paulo: LTC, 1995;

OLIVEIRA, Ariovaldo Umbelino de. Modo Capitalista de Produção e Agricultura. São Paulo: Ática, 1990;

PIGNARRE, Philippe. O que é um medicamento?: Um objeto estranho entre ciência, mercado e sociedade. São Paulo: Editora 34, 1999;

SANTOS, José Vicente Tavares dos. Colonos do Vinho. São Paulo: Hucitec, 1978;

SHANIN, THeodor. A definição de camponês: conceituações e desconceituações. $O$ velho e o novo em uma discussão marxista. Revista Estudos CEBRAP 26. Petropolis: Ed. Vozes, 1980. p. 43-79.

Recebido para publicação em outubro de 2010 Aprovado para publicação em dezembro de 2010 